\title{
Designing and planning a rice supply chain: a case study for Iran farmlands
}

\author{
Seyyed Aziz Seyyed Jifroudia ${ }^{\mathbf{a}}$ Ebrahim Teimoury ${ }^{\mathbf{b}^{*}}$ and Farnaz Barzinpour ${ }^{\mathrm{b}}$
}

${ }^{a}$ Ph.D. candidate, School of Industrial Engineering, Iran University of Science and Technology, Iran ${ }^{b}$ Associate Professor, School of Industrial Engineering, Iran University of Science and Technology, Iran

\begin{tabular}{l}
\hline C H R O N I C L E \\
\hline Article history: \\
Received December 10, 2019 \\
Received in revised format: \\
December 28, 2019 \\
Accepted January 14, 2020 \\
Available online \\
January 14, 2020 \\
\hline Keywords: \\
Supply chain management \\
Agriculture \\
Agri-food supply chain \\
Rice supply chain \\
Cropping pattern
\end{tabular}

\begin{abstract}
A B S T R A C T
Agricultural food supply chains of different grains such as wheat, rice, and corn include several processes from cropping and harvesting to distribution. Integrating these processes to reduce costs, in addition to providing sufficient supply, are of the major goals of agri-food supply chain management. Rice is an important grain that constitutes an important part of people's diets throughout the world. FAO predicts that global rice utilization would increase over the next few years. Considering rice's importance, in this paper, a mixed-integer linear mathematical model for designing and planning of rice supply chain is proposed which aims to maximize total profit by integrating different decisions of the rice supply chain including supplier selection, cropping, fertilizing, pest control, harvesting, milling, transportation, and distribution. This model considers different rice varieties and takes into account irrigation water requirements of crops and available water resources. A case study of Iran farmlands in Gilan province is employed to show the applicability and advantages of the proposed model for the rice supply chain. Results indicate that increasing conversion ratio of paddy to rice and reducing labor costs would have a significant impact on the total profit of the supply chain.
\end{abstract}

C) 2020 by the authors; licensee Growing Science, Canada.

\section{Introduction}

Food is an important product all around the world and is produced in different forms. As Van Wart et al. (2013) declared, it is straightforward that the more world population is, the more food consumption. It is estimated that there will be a $35 \%$ increase in population by 2050 . Therefore, it could be concluded that, as resources become scarce, access to food decreases. Iran is the second-largest country in the Middle East and its territory spans 1,648,195 $\mathrm{km}^{2}$. About one-third of Iran's land area is proper for farmland, although prominent areas are not cultivable due to lack of water resources and poor soil (low nutrients, high salts and not rich in organic matter). In Iran, agriculture consumes 86 billion cubic meters of 94 billion cubic meters of harvested water $(91.5 \%)$ which is higher than the global average. Also, FAO in country Programming Framework (2012) reported that irrigation consumes about 92\% of groundwater that can cause water shortage and soil salinity in the future. Rice as an important grain that constitutes an important part of people's diet throughout the world, can be undoubtedly considered as a staple food. Financial Tribune (2015) reported that rice consumption in Iran is 7 times more than the European Union with an annual consumption equal to $36.6 \mathrm{~kg}$ per capita, in contrast to $5.3 \mathrm{~kg}$ for EU members. As many people consume it, the state of quality and healthiness are under public scrutiny. To guarantee the quality and healthiness of the food, the process of farm to fork should be put under consideration. Also, since rice is a staple food, its supply should be planned carefully in order to * Corresponding author. Tel.: (+9821)73225022 E-mail address: Teimoury@iust.ac.ir (E. Teimoury) 
guarantee food security. Mangan and Christopher (2005) stated that designing a well-defined supply chain of agri-food not only ensures the continuity of rice supply but also ensures the consumers and the authorities that the products are healthy.

This paper aims to design and plan the rice supply chain in a way that takes cropping, milling, and distribution into account. Optimizing different decisions such as determining the optimal flow between different stages of the supply chain, the amount of area under cultivation, and milling center selection are under consideration. Integrating the stages of the supply chain in the provided mathematical model prevents obtaining sub-optimal solutions. As rice is a staple food in Iran, a case study is conducted to validate the proposed model and show its application in real-life situations.

The rest of this paper is organized as follows: First, the related researches are reviewed to find the research gap in section 2. Then the problem is described in detail to present the framework of research in section 3. The mathematical formulation is stated in section 4 . The case study is presented in section

5 in detail. Then, the results and the sensitivity analyses are discussed in sections 6 and 7, respectively. Finally, conclusions and future research opportunities are provided in section 8.

\section{Literature review}

Supply chain management is a set of approaches used to coordinate suppliers, manufacturers, warehouses, and retailers in order to minimize costs (or maximize profits) in addition to maintaining customer service levels. Agri-food supply chains are composed of different processes that are responsible for bringing food from farm to fork. These processes include cultivation, harvesting, processing, and distribution. Agri-food supply chains have received the attention of many researchers, and there is a rich body of literature in this area. Clarke (1989) presented a mathematical model to determine the optimal cropping pattern in order to maximize the return from agricultural land. The objective function was to maximize total profit. Diversifying crops on land is an important tool that can increase the return from the agricultural land. Additionally, using proper seed, fertilizer, and pesticide plays an important role in making healthy products. Annetts and Audsley (2002) considered the problem of cropping by developing a multi-objective mathematical model for different agricultural conditions. In this paper, the objective function is maximizing total profit. Moreover, inventory control, and perishability of products are taken under consideration.

Higgins and Laredo (2006) investigated harvesting, and transportation decisions of the sugar supply chain in Australia. Since Australian sugar industry suffers from financial problems, the proposed model aims to minimize total costs. Ferrer et al. (2008) examined the harvest-scheduling problem, and provided a heuristic solution approach for the mixed-integer linear model. Additionally, labor allocation, and routing decisions are considered. A quality loss function was used to optimally determine harvest date, and a real case study was presented in this research. Aryanezhad and Jabbarzadeh (2009) presented a paper regarding integrated inventory-location model with random disruption. The author addressed the problem of supply chain design when distribution centers were liable to random disruption, meaning one or more distribution centers could be unable to provide service at any time. They formulated the model with the objective function of minimizing inventory, shipping, and sales costs. To solve the model, the authors used the genetic algorithm. Ali et al. (2009) presented the problem of infield logistics, and formulated it as an integer linear programming vehicle routing problem. The vehicle operations are carried out in order to perform crop harvesting. Piewthongngam et al. (2009) investigated the problem of lack of integration between farms, and milling centers, which leads to excessive supply to milling centers (more than their capacities). To optimally plan farms, and milling centers, cultivation planning was conducted to determine the cultivation time, cultivar selection, and harvesting time. The objective function was maximizing total sugar production and a case study of milling in Thailand was considered. Blanco et al. (2010) investigated the cooperation in the agriculture supply chain in the field of maize, and forage harvesting. In this problem, 
a linear mixed-integer programming model is proposed aiming to minimize the total working time of machines.

Cai et al. (2010) examined the problem of optimization, and coordination of fresh agricultural food supply chain. The considered network has long haul transportations. However, the distributor must use an appropriate method to keep the products fresh. Therefore, to determine order quantity, centralized and decentralized states of coordination have been examined to maximize total manufacturer and distributor profits. Bohle et al. (2010) developed a robust optimization model for scheduling the harvesting of grapes. Due to existing uncertainties in phenomena, it is important to develop a model that enhances productivity, and improves the situation at the harvest stage. The developed robust optimization model was solved for a real case problem. Márquez et al. (2011) examined a multiobjective crop planning problem, and optimized the model using a pareto-based evolutionary algorithm. Due to the importance of saving water resources, the proposed model maximizes total profit while minimizing water consumption. In this problem, real data is collected from several greenhouses in Spain. Zhang and Li (2012) presented an e-business-based agri-food supply chain to optimize internal costs, and productivity. In fact, they used RFID technology for information sharing to coordinate the supply chain.

Tan and Çömden (2012) examined the annual agricultural cropping pattern considering harvest, and yield risk. This study presented a planning approach for a company that aims to estimate annual supply. The goal was to maximize profits, and a contract was used to coordinate supply chain members. Esmaeilikia et al. (2016) proposed new approaches for supply chain flexibility to deal with operational risks. In fact, the contribution of this paper was to deal with supply chain risks using a flexible approach while taking into account disruptive risks. The paper's supply chain includes suppliers, factories, distribution centers, and end customers. Madadi et al. (2014) proposed a model concentrating on the quality of raw materials that can affect the whole supply chain. In this paper, the reduction in the amount of contaminated raw material by manufacturer is examined. The proposed model considers strategic decisions as well as tactical ones, and aims to minimize total costs.

Thoucharee et al. (2017) presented a mathematical model for rice inventory planning and transportation from farms to milling centers, and from milling centers to export and wholesale ports. The results are obtained using a meta-heuristic algorithm. Hossain and Jahan (2018) assessed the weaknesses of the informal rice milling industry in Bangladesh. They also examined the benefits of creating centralized and specialized industrial zones. These centralized industrial areas can be created by clustering. Ahmadi et al. (2018) presented models of decision support systems for fresh fruits and vegetables in order to plan and coordinate the related supply chain in strategical, tactical and operational levels. The objective is to maximize profit. Cheraghalipour et al. (2019) considered the rice supply chain and provided a bilevel model for rice supply chain management. The objective function is to minimize total cost. The authors used meta-heuristic algorithms to optimize the proposed NP-hard problem.

Based on the literature review, the following contributions will be considered in this paper. The comparison of the present study with the previous researches is presented in Table 1.

- This study considers irrigation water consumption, since reducing surface and groundwater withdrawal is an important national issue;

- This paper integrates all the decisions related to the supply chain in order to avoid sub-optimality. To the best of our knowledge, there are few studies that consider all processes from farm to fork.

- The combination of fertilizers required for growing rice in each region is considered in this paper;

- The pesticide needed for growing rice in each region is taken into consideration. 


\section{Table 1}

Comparison of present research vs. recent studies

\begin{tabular}{|c|c|c|c|c|c|c|c|c|c|c|c|c|c|c|c|}
\hline \multirow[b]{2}{*}{ Author(s) } & \multirow[b]{2}{*}{ 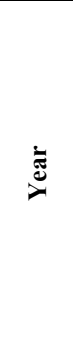 } & \multicolumn{6}{|c|}{ Decisions } & \multicolumn{6}{|c|}{ Objective function(s) } & \multirow[b]{2}{*}{ 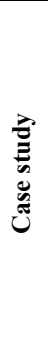 } & \multirow[b]{2}{*}{ 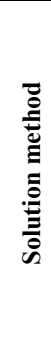 } \\
\hline & & $\begin{array}{l}\stackrel{\infty}{\Xi} \\
\stackrel{\Xi}{0} \\
\stackrel{0}{0} \\
\stackrel{0}{0}\end{array}$ & $\stackrel{\infty}{\stackrel{\Xi}{\Xi}}$ & 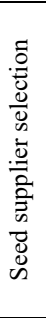 & 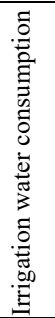 & 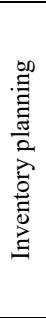 & 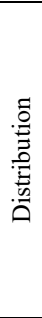 & 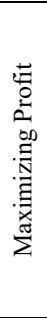 & 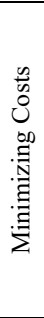 & 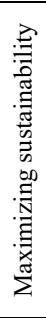 & 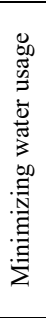 & 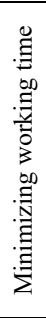 & 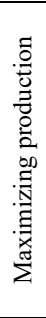 & & \\
\hline Clarke & 1989 & $\sqrt{ }$ & & & & & & $\sqrt{ }$ & & & & & & $\sqrt{ }$ & $E$ \\
\hline Annetts & 2002 & $\sqrt{ }$ & & & & & & $\sqrt{ }$ & & $\sqrt{ }$ & & & & $\sqrt{ }$ & E \\
\hline Higgins & 2006 & & & & & & & & $\sqrt{ }$ & & & & & $\sqrt{ }$ & $\mathrm{H}$ \\
\hline Ferrer & 2008 & & & & & & & & $\sqrt{ }$ & & & & & $\sqrt{ }$ & $\mathrm{H}$ \\
\hline Ali & 2009 & $\sqrt{ }$ & & & & & & & $\sqrt{ }$ & & & $\sqrt{ }$ & & & $\mathrm{E}$ \\
\hline Piewthongngam & 2009 & $\sqrt{ }$ & & & & & & & & & & & $\sqrt{ }$ & $\sqrt{ }$ & $\mathrm{H}$ \\
\hline Blanco & 2010 & & & & & & & & & & & $\sqrt{ }$ & & & $\mathrm{H}$ \\
\hline Cai & 2010 & & & & & & $\sqrt{ }$ & & $\sqrt{ }$ & & & & & & $\mathrm{D}$ \\
\hline Bohle & 2010 & & & & & & & & $\sqrt{ }$ & & & & & & $\mathrm{S}$ \\
\hline Marquez & 2011 & $\sqrt{ }$ & & & $\sqrt{ }$ & & & $\sqrt{ }$ & & & $\sqrt{ }$ & & & $\sqrt{ }$ & MH \\
\hline Tan & 2012 & $\sqrt{ }$ & & & & & & $\sqrt{ }$ & & & & & & $\sqrt{ }$ & $\mathrm{E}$ \\
\hline Thoucharee & 2017 & & & & & & $\sqrt{ }$ & & $\sqrt{ }$ & & & & & & MH \\
\hline Hossain & 2018 & & $\sqrt{ }$ & & & & & & $\sqrt{ }$ & & & & & $\sqrt{ }$ & $E$ \\
\hline Ahmadi & 2018 & $\sqrt{ }$ & & & & & & $\sqrt{ }$ & & & & & & & $\mathrm{E}$ \\
\hline Cheraghalipour & 2019 & & & & & $\sqrt{ }$ & $\sqrt{ }$ & & $\sqrt{ }$ & & & & & & MH \\
\hline This paper & 2019 & $\sqrt{ }$ & $\sqrt{ }$ & $\sqrt{ }$ & $\sqrt{ }$ & $\sqrt{ }$ & $\sqrt{ }$ & $\sqrt{ }$ & & & & & & $\sqrt{ }$ & $\mathrm{E}$ \\
\hline
\end{tabular}

\section{Problem statement}

Consider a single farming company (Nahid Aseman Iranian Co.), which specializes in the cultivation, production, and distribution of rice. The rice supply chain includes the stages of cropping, milling, and distribution. This company's supply chain network is shown in Fig. 1.

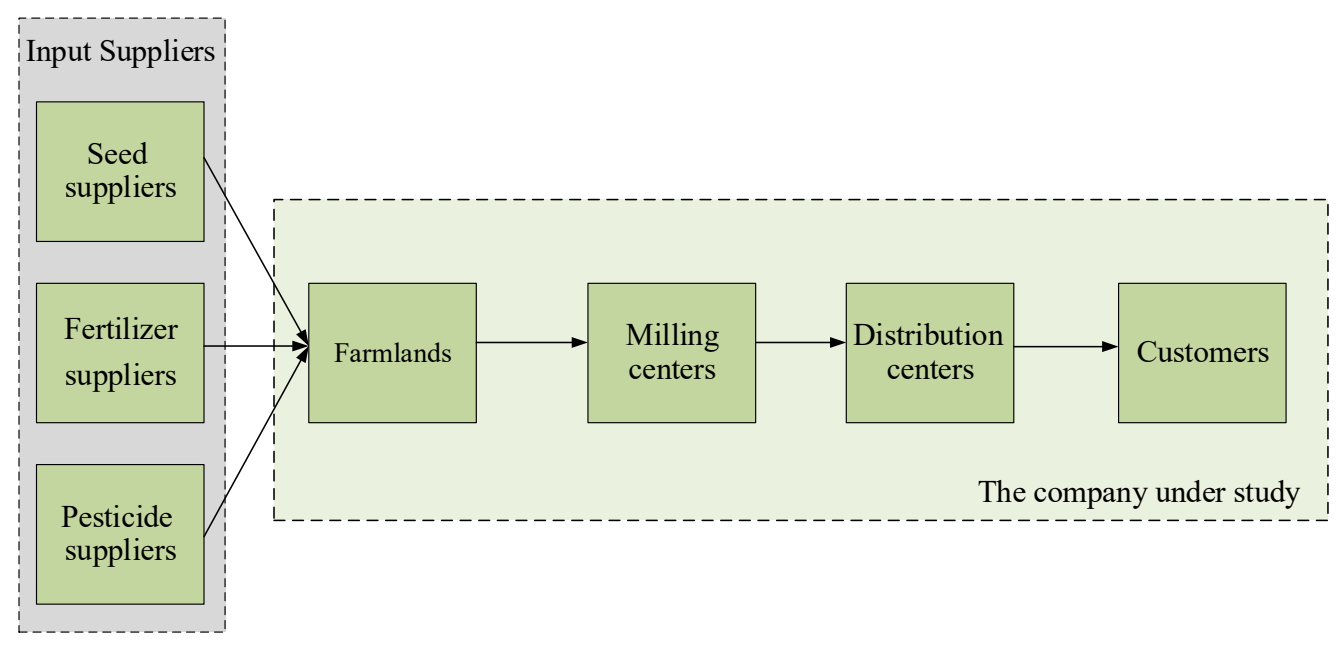

Fig. 1. The rice supply chain network of the company understudy

This company owns agricultural lands in different regions. As rice varieties differ in yield, irrigation requirements, and costs, this company aims to determine the best cropping pattern to maximize profit. The cultivation process includes land preparation, seed sowing, irrigation, fertilization, and pest control. After harvesting, paddies are transported to milling centers where they are converted to final products including rice, broken rice, bran, and husk. Then final products are transported to distribution centers where they are held and transported to customers. The company should make integrated decisions for cropping, milling, and distribution to avoid sub-optimality. A mathematical model is 
formulated to simultaneously make decisions regarding the whole supply chain. These strategic and tactical decisions are listed in the following:

- Selecting the varieties of rice for cropping

- Selecting the regions to crop, and determining the area under cultivation

- Supplier selection for seeds, fertilizers, and pesticides

- Selecting milling centers

- Transportation, and distribution planning

\section{Mathematical formulation}

Model assumptions are as follows:

- Seeds, fertilizers, and pesticides are provided by suppliers when they are needed. In other words, the company does not store seeds, fertilizers or pesticides.

- Irrigation water requirements, fertilizers, and pesticides needs of crops must be fully satisfied.

- Milling centers differ in conversion ratio since they use different technologies.

- Required labor for cultivation and harvesting of rice is independent of the variety of cultivated rice.

- A different combination of fertilizers is required for growing rice in each region.

- A different combination of pesticides is required for growing rice in each region.

- Total irrigation water requirements cannot exceed the available amount of surface and groundwater.

The mathematical model involves indices and sets, parameters, decision variables, objective functions, and the constraints, which are presented in the following.

\subsection{Indices and sets}

$\begin{array}{ll}i \in\{1,2,3,4,5\} & \text { Rice varieties } \\ l \in\{1,2,3\} & \text { Regions } \\ f \in\{1,2,3\} & \text { Fertilizers } \\ p \in\{1,2\} & \text { Pesticides } \\ m \in\{1, \ldots, M\} & \text { Milling centers } \\ d \in\{1, \ldots, D\} & \text { Distribution centers } \\ e \in\{1, \ldots, E\} & \text { Customer zones } \\ r \in\{1,2,3\} & \text { Final products (Rice, broken rice and bran) } \\ s \in\{1, \ldots, S\} & \text { Suppliers }\end{array}$

\subsection{Parameters}

$Y L D_{i l} \quad$ Yield of rice variety $i$ in region $l$

$I W_{i l} \quad$ Irrigation requirement of rice variety $i$ in region $l$

$A S W_{l} \quad$ Available surface water in region $l$ that can be dedicated to irrigation

$A G W_{l} \quad$ Available groundwater in region $l$

$M g_{l} \quad$ Groundwater mining allowance coefficient in region $l$

$\eta_{l} \quad$ Irrigation efficiency in region $l$

$C S W_{l} \quad$ Cost of surface water in region $l$

$C G W_{l} \quad$ Cost of groundwater in region $l$

$A_{l} \quad$ Available irrigation land in region $l$ 
$C L_{l} \quad$ Cost of land preparation in region $l$

$C S_{l} \quad$ Sowing cost of rice in region $l$

$\mathrm{CH}_{l} \quad$ Harvesting cost in region $l$

$S A_{i} \quad$ The amount of seed required for the cultivation of rice variety $i$

$P S_{i s} \quad$ Purchasing cost of seed $i$ from supplier $S$

$F A_{i l f} \quad$ The amount of fertilizer type $f$ required for growing rice variety $i$ in region $l$

$P F_{f s} \quad$ Purchasing cost of fertilizer type $f$ from supplier $s$

$C P_{p s} \quad$ Purchasing cost of pesticide type $p$ from supplier $s$

$P A_{i l p} \quad$ The amount of pesticide type $p$ required for rice variety $i$ in region $l$

$C L B_{l} \quad$ Labor cost in region $l$

$L C \quad$ Required labor for cultivation and harvesting of rice

$T C S_{s l} \quad$ Transportation cost of rice seeds from supplier $s$ to region $l$

$T C F_{s l} \quad$ Transportation cost of fertilizers from supplier $s$ to region $l$

$T C P_{s l} \quad$ Transportation cost of pesticides from supplier $s$ to region $l$

$T C_{l m} \quad$ Transportation cost of paddy from region $l$ to milling center $m$

$T C^{\prime}{ }_{m d} \quad$ Transportation cost of final products form milling center $m$ to distribution center $d$

$T C^{\prime \prime}$ de Transportation cost of final products from distribution center $d$ to customer $e$

$D_{r e} \quad$ Demand of customer $e$ for product type $r$

$P R_{r e} \quad$ Selling price of product type $r$ to customer $e$

$C A P_{d} \quad$ Handling capacity of distribution center $d$

$I I_{r d} \quad$ Initial inventory of product type $r$ in distribution center $d$

$C A P M_{m}$ Capacity of milling center $m$

$C A P S_{i s} \quad$ Capacity of supplier $s$ for providing rice seed $i$

$C A P F_{f s} \quad$ Capacity of supplier $s$ for providing fertilizer type $f$

$C A P P_{p s} \quad$ Capacity of supplier $s$ for providing pesticide type $p$

$H_{r d} \quad$ Holding cost of product type $r$ in distribution center $d$

$\mathrm{PRO}_{m} \quad$ Processing cost at milling center $m$

$\alpha_{r m} \quad$ Conversion ratio of paddy to final product $r$ in milling center $m$

\subsection{Decision variables}

$S W_{l} \quad$ Amount of surface water used for irrigation in region $l$

$G W_{l} \quad$ Amount of groundwater used for irrigation in region $l$

$X S_{i s l} \quad$ Quantity of rice seed $i$ transported from supplier $s$ to region $l$

$X F_{f s l} \quad$ Quantity of fertilizer $f$ transported from supplier $s$ to region $l$

$X P_{p s l} \quad$ Quantity of pesticide $p$ transported from supplier $s$ to region $l$

$X C_{i l} \quad$ Planting area of rice variety $i$ in region $l$

$X_{i l m} \quad$ Quantity of paddy type $i$ transported from region $l$ to milling center $m$

$X_{r m d}^{\prime} \quad$ Quantity of final product type $r$ transported from milling center $m$ to distribution center $d$

$Y_{\text {rde }} \quad$ Quantity of final product type $r$ transported from distribution center $d$ to customer

$\begin{array}{ll}I_{r d} & \text { zone } e \\ & \text { Final inventory of product type } r \text { in distribution center } d\end{array}$

$Z_{m} \quad 1$ if milling center $m$ is used for processing

\subsection{Mathematical model}

The objective function maximizes total profit in Eq. (1) to Eq. (10). Eq. (1) is Sales revenue. Eq. (2) is the cost of purchasing and transportations of rice seeds. Eq. (3) presents the costs of purchasing and transportation of fertilizers. Eq. (4) is the cost of purchasing and transportation of pesticides. The Cost 
of transporting paddies to milling centers is presented in Eq. (5). Eq. (6) shows the cost of transporting final products to distribution centers. Eq. (7) is the cost of transporting final products to customers. Eq. (8) shows the holding costs in distribution centers. Eq. (9) is the processing costs in milling centers. Finally, Eq. (10) is the costs of land preparation, seed sowing, harvesting, labor work, and water

$$
\begin{aligned}
\max _{O B J}=\sum_{r} \sum_{d} \sum_{e} P R_{r e} \cdot Y_{r d e} \\
-\sum_{i} \sum_{s} \sum_{l}\left(P S_{i s}+T C S_{s l}\right) \cdot X S_{i s l} \\
-\sum_{f} \sum_{s} \sum_{l}\left(P F_{f s}+T C F_{s l}\right) \cdot X F_{f s l} \\
-\sum_{p} \sum_{s} \sum_{l}\left(C P_{p s}+T C P_{s l}\right) \cdot X P_{p s l} \\
-\sum_{i} \sum_{l} \sum_{m} T C_{l m} \cdot X_{i l m} \\
-\sum_{r} \sum_{m} \sum_{d} T C^{\prime}{ }_{m d} \cdot X^{\prime}{ }_{r m d} \\
-\sum_{r} \sum_{d} \sum_{e} T C^{\prime \prime}{ }_{d e} \cdot Y_{r d e} \\
-\sum_{r} \sum_{d}^{H_{r d} \cdot I_{r d}} \\
-\sum_{i} \sum_{l} \sum_{m} P R O_{m} \cdot X_{i l m} \\
-\sum_{i} \sum_{l}\left[C L_{l}+C S_{l}+C H_{l}+C L B_{l} \cdot L C\right] \cdot X C_{i l} \\
-\sum_{l}\left(C S W_{l} \cdot S W_{l}+C G W_{l} \cdot G W_{l}\right)
\end{aligned}
$$

subject to

$$
\begin{array}{ll}
\sum_{r} \sum_{m} X_{r m d}^{\prime} \leq C^{\prime} A P_{d} & \forall d \\
\sum_{i} \sum_{l} X_{i l m} \leq C A P M_{m} \cdot Z_{m} & \forall m \\
Z_{m} \leq \sum_{i} \sum_{l} X_{i l m} & \forall m \\
\sum_{d} Y_{r d e} \leq D_{r e} & \forall r, e \\
I I_{r d}+\sum_{m} X_{r m d}^{\prime}-\sum_{e} Y_{r d e}-I_{r d}=0 & \forall r, d \\
\sum_{d} X^{\prime}{ }_{r m d}=\sum_{i} \sum_{l} \alpha_{r m} \cdot X_{i l m} & \forall r, m \\
\sum_{i} X C_{i l} \leq A_{l} & \forall l \\
S W_{l} \leq A S W_{l} & \forall l \\
G W_{l} \leq M g_{l} \cdot A G W_{l} & \forall l \\
\sum_{i} I W_{i l} \cdot X C_{i l}-\eta\left(S W_{l}+G W_{l}\right) \leq 0 & \forall l \\
\sum_{S} X S_{i s l}=S A_{i} . X C_{i l} & \forall i, l \\
\sum_{l} X S_{i s l} \leq C A P S_{i s} & \forall i, s
\end{array}
$$




$$
\begin{array}{ll}
\sum_{s} X F_{f s l}=\sum_{i} F A_{i l f} \cdot X C_{i l} & \forall f, l \\
\sum_{l} X F_{f s l} \leq C A P F_{f s} & \forall f, s \\
\sum_{s} X P_{p s l}=\sum_{i} P A_{i l p} \cdot X C_{i l} & \forall p, l \\
\sum_{l} X P_{p s l} \leq C A P P_{p s} & \forall p, s \\
\sum_{f} Y L D_{i l f} \cdot X C_{i l}=\sum_{m} X_{i l m} & \forall i, l \\
S W_{l}, G W_{l}, X S_{i s l} X F_{f s l}, X P_{p s l}, X C_{i l}, X_{i l m}, X_{r m d}^{\prime}, Y_{r d e}, I_{r d} \geq 0, Z_{m} \in\{0,1\}
\end{array}
$$

Constraint (11) ensures the handling capacity constraint of distribution centers. The processing capacity of operating milling centers is shown in constraint (12). Quantity of transported final products to each customer zone cannot exceed its demand, which is presented in constraint (14). Constraint (15) guarantees that the outflow of distribution centers cannot exceed the inventory on hand. Constraint (16) calculates the quantity of final products based on the conversion ratio of milling centers. Maximum available land is presented in constraint (17). Surface water constraint is presented in (18). Constraint (19) presents the maximum available groundwater resources in each region. Constraint (20) calculates the irrigation water requirements in each region. Constraint (21) calculates the required quantity of rice seeds. Constraint (22) shows the maximum capacity of each supplier for providing rice seeds. Constraint (23) calculates the required quantity of fertilizers and constraint (24) is the maximum capacity of each supplier for providing each fertilizer. Constraint (25) calculates the required quantity of pesticides and constraint (26) is the maximum capacity of each supplier for each pesticide. Constraint (27) determines the amount of harvested paddies. The last constraint (28) determines decision variables and their types.

\section{Case study}

In this section, a real case of Iran farmlands (Nahid Aseman Iranian Co.) is considered to validate the proposed model and investigate its applicability in real-life situations. This company cultivates five rice varieties consisting of three local types and two high-yield types. Also, three final products are extracted from rice paddies including rice, broken rice, and bran and husk. Nahid Aseman Iranian Co. has six major customers, which differentiate in demand and selling price. The prices are presented in Table 2.

\section{Table 2}

Selling price of final products in each customer zone (Iranian Million Rial/tonnes)

\begin{tabular}{ccccccc}
\hline \multirow{2}{*}{ Final product } & \multicolumn{7}{c}{ Customer } \\
\cline { 2 - 7 } & 1 & 2 & 3 & 4 & 5 & 6 \\
\hline Rice & 90 & 90 & 100 & 100 & 120 & 0 \\
Broken rice & 45 & 45 & 50 & 50 & 60 & 120 \\
Bran and husk & 0 & 0 & 0 & 0 & 0 & 110 \\
\hline
\end{tabular}

The area of the company's farmlands is listed in Table 3. These lands are all placed in Gilan province. However, Gilan province is divided into three sections: center, west, and east as shown in Fig. 2. Moreover, this company has three major distribution centers in the center, west, and east of Gilan province. Additionally, Three main suppliers are considered in this paper including 1) Local suppliers 2) Agricultural Support Services Co. 3) Wholesalers. 
Table 3

Area and preparation cost of farmlands

\begin{tabular}{cccc}
\hline Province & Regions & Area $\left(\mathrm{ha}^{2}\right)$ & Price (Iranian Million Rial) \\
\hline \multirow{3}{*}{ Gilan } & Center & 1000 & 15 \\
& West & 500 & 15 \\
& East & 5000 & 15 \\
\hline
\end{tabular}

The irrigation water requirement of each rice variety, which depends on the land's location is presented in Table 4. The available surface and groundwater resources in Gilan and annual milling allowance coefficient from groundwater recourses in each region can be observed in Table 5.

Table 4

Irrigation water requirement of each rice variety $\left(\mathrm{m}^{3} / \mathrm{ha}\right)$

\begin{tabular}{ccccc}
\hline Rice varieties/Section & & Center & West & East \\
\hline \multirow{2}{*}{ Local } & 1 & 9000 & 8000 & 9000 \\
& 2 & 9000 & 8000 & 9000 \\
& 3 & 9000 & 8000 & 9000 \\
\hline \multirow{2}{*}{ High-yield } & 4 & 10000 & 9000 & 10000 \\
& 5 & 10000 & 9000 & 10000 \\
\hline
\end{tabular}

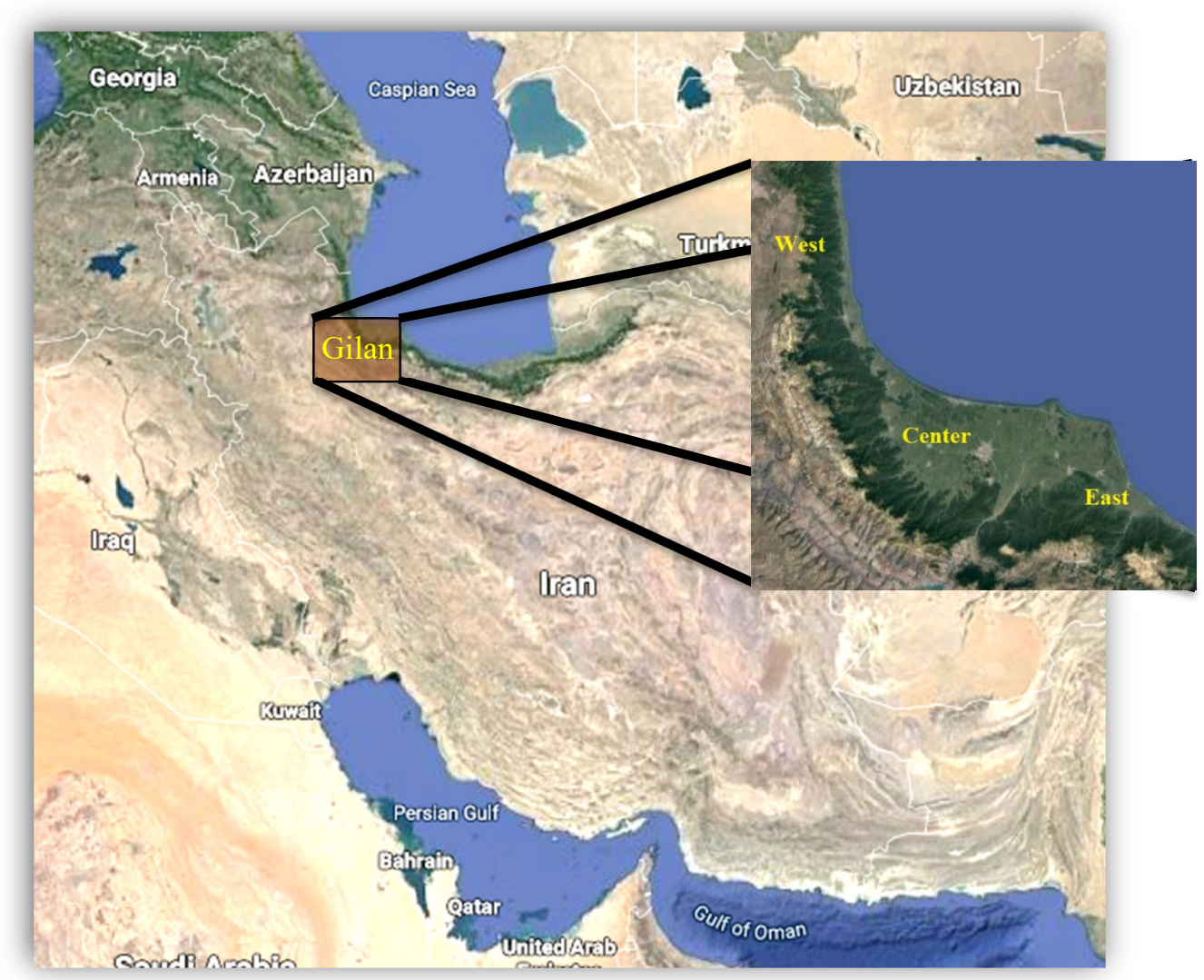

Fig. 2. Sections (regions) of Gilan province, Iran 


\section{Table 5}

Available water resources and Groundwater mining allowance coefficient in each region

\begin{tabular}{|c|c|c|c|c|c|c|}
\hline \multirow[b]{3}{*}{ Province } & \multirow{3}{*}{ 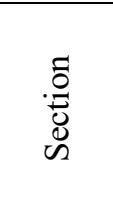 } & \multicolumn{5}{|c|}{ Water resources $\left(\mathrm{m}^{3}\right)$} \\
\hline & & \multicolumn{2}{|c|}{ Surface water } & \multicolumn{3}{|c|}{ Groundwater } \\
\hline & & $\begin{array}{l}\text { Available } \\
\text { resource }\left(\mathrm{m}^{3}\right)\end{array}$ & $\begin{array}{c}\text { Cost } \\
\text { (Iranian } \\
\text { Rial) }\end{array}$ & $\begin{array}{l}\text { Available } \\
\text { resource }\left(\mathrm{m}^{3}\right)\end{array}$ & $\begin{array}{l}\text { Milling allowance } \\
\text { coefficient }\end{array}$ & $\begin{array}{c}\text { Cost } \\
\text { (Iranian } \\
\text { Rial) }\end{array}$ \\
\hline \multirow{3}{*}{ Gilan } & Center & 14347826 & 650 & 2057971 & 0.75 & 1667 \\
\hline & West & 3175676 & 650 & 3452703 & 0.14 & 1667 \\
\hline & East & 34210526 & 650 & 16894737 & 0.21 & 1667 \\
\hline
\end{tabular}

Irrigation efficiency (water application efficiency) is considered 0.6 in the center of Gilan, 0.5 in the western section, and 0.5 in the eastern section. To deter, incapacitate, kill or discourage pests, chemical or biological pesticides are used. The procurement prices of pesticides are presented in Table 6 .

Table 6

Pesticides' suppliers and prices (Iranian Rial per kg)

\begin{tabular}{ccc}
\hline Pesticide/Supplier & Agricultural Support Services Co. & Wholesalers \\
\hline 1 & 1950000 & 1950000 \\
2 & 3400000 & 3400000 \\
\hline
\end{tabular}

Moreover, fertilizer is a chemical or natural substance added to soil or land to increase its fertility. Fertilizers' details can be observed in Table 7.

Table 7

Fertilizers' suppliers and prices (Iranian Rial per kg)

\begin{tabular}{ccc}
\hline Fertilizer/Supplier & Agricultural Support Services Co. & Wholesalers \\
\hline Urea & 8600 & 8600 \\
Potassium Sulfate & 11200 & 11200 \\
Triple Super Phosphate & 15000 & 15000 \\
\hline
\end{tabular}

The demand of each customer zone for final products is listed in Table 8 .

Table 8

Demands of each customer zone for final products (tonnes)

\begin{tabular}{ccccccc}
\hline Product/Customer zone & 1 & 2 & 3 & 4 & 5 & 6 \\
\hline Rice & 5000 & 3000 & 1500 & 2000 & 100000 & 0 \\
Broken rice & 0 & 0 & 0 & 0 & 0 & 100000 \\
Bran and husk & 0 & 0 & 0 & 0 & 0 & 100000 \\
\hline
\end{tabular}

The conversion ratio of paddy to final products is listed in Table 9.

Table 9

Conversion ratio of paddy to final products

\begin{tabular}{cccc}
\hline Product & \multicolumn{3}{c}{ milling center } \\
\cline { 2 - 4 } & 1 & 2 & 3 \\
\hline Rice & 0.6 & 0.6 & 0.6 \\
Broken rice & 0.2 & 0.2 & 0.2 \\
Bran and husk & 0.1 & 0.1 & 0.1 \\
\hline
\end{tabular}


Paddies are processed at milling centers. The capacity of milling centers can be observed in Table 10.

Table 10

Capacity of milling centers (tonnes)

\begin{tabular}{cc}
\hline Milling center & Capacity \\
\hline 1 & 8000 \\
2 & 2500 \\
3 & 12000 \\
\hline
\end{tabular}

The yield of rice varieties in each region and the procurement prices of rice seeds from each supplier is presented in Table 11.

Table 11

Yield of rice varieties, and procurement price of rice seeds (tones $/ \mathrm{ha}^{2}$ )

\begin{tabular}{|c|c|c|c|c|c|c|}
\hline \multirow{2}{*}{\multicolumn{2}{|c|}{ Rice variety }} & \multicolumn{2}{|c|}{$\begin{array}{c}\text { Price } \\
\text { (Iranian Rial) }\end{array}$} & \multicolumn{3}{|c|}{ Gilan } \\
\hline & & Local suppliers & $\begin{array}{l}\text { Agricultural Support } \\
\text { Services Co. }\end{array}$ & Center & West & East \\
\hline \multirow{3}{*}{ Local } & 1 & 80000 & 100000 & 2.1 & 2.1 & 2.1 \\
\hline & 2 & 70000 & 90000 & 2.1 & 2.1 & 2.1 \\
\hline & 3 & 65000 & 80000 & 2.1 & 2.1 & 2.1 \\
\hline \multirow{2}{*}{ High-yield } & 4 & 65000 & 75000 & 3 & 3 & 3 \\
\hline & 5 & 63000 & 70000 & 3 & 3 & 3 \\
\hline
\end{tabular}

\section{Computational results}

The proposed mathematical model is solved using GAMS 24.7.4 on a computer with Intel® Core ${ }^{\mathrm{TM}}$ i76500U 2.5 GHz, and 16GB DDR4 Memory. The data used is provided in the previous section. The results of the model are presented in the following. The optimal value of the objective function is $3.078 \times 10^{11}$. This value is the total profit of the supply chain. In the optimal solution, only one of the high-yield varieties (rice variety 5) is cultivated. Moreover, all available land is used for cropping. The results are presented in Table 12 . Also, $87 \%$ of milling capacity is used in the optimal solution. The optimal flows of paddies between farmlands and milling centers are presented in Table 13.

Table 12

Optimal planting area $\left(\mathrm{ha}^{2}\right)$

\begin{tabular}{cccc}
\hline \multirow{2}{*}{ Rice variety } & \multicolumn{3}{c}{ Regions } \\
\cline { 2 - 4 } & Center & West & East \\
\hline 1 & 0 & 0 & 0 \\
2 & 0 & 0 & 0 \\
3 & 0 & 0 & 0 \\
4 & 0 & 0 & 0 \\
5 & 1000 & 500 & 5000 \\
\hline
\end{tabular}

Table 13

Optimal paddy flow between farmlands (regions) and milling centers

\begin{tabular}{|c|c|c|c|}
\hline \multirow{2}{*}{ Region } & \multicolumn{3}{|c|}{ Rice variety 5} \\
\hline & MC 1 & MC 2 & MC 3 \\
\hline Center & 3000 & 0 & 0 \\
\hline West & 1500 & 0 & 0 \\
\hline East & 500 & 2500 & 12000 \\
\hline
\end{tabular}


Surface water withdrawal for irrigating crops in each region is presented in Table 14. As can be seen, surface water resources are sufficient for irrigation requirements completely. Therefore, Groundwater resources are not used

Table 14

Water withdrawal $\left(\mathrm{m}^{3}\right)$

\begin{tabular}{lll}
\hline Region & Surface water & Groundwater \\
\hline Center & 3333333 & 0 \\
West & 1800000 & 0 \\
East & 20000000 & 0 \\
\hline
\end{tabular}

The optimal flows of products between milling centers and distribution centers are presented in Table 15. The optimal flows of products from distribution centers to customer zones are presented in Table 16. Also, the flow of rice seeds, and fertilizers from suppliers to farmlands are presented in Tables 17 and 18 , respectively.

Table 15

Optimal product flows (tones) between milling centers and distribution centers (DC)

\begin{tabular}{ccccc}
\hline Final products & Milling Center & DC 1 & DC 2 & DC 3 \\
\hline \multirow{2}{*}{ Rice } & 1 & 1450 & 1550 & 0 \\
& 2 & 1500 & 0 & 0 \\
Broken rice & 3 & 0 & 0 & 7200 \\
& 1 & 1000 & 0 & 0 \\
\hline \multirow{3}{*}{ Bran and husk } & 2 & 500 & 0 & 0 \\
& 3 & 0 & 0 & 2400 \\
\hline
\end{tabular}

Table 16

Optimal product flow (tones) from distribution centers (DCs) to customer zones

\begin{tabular}{cccc}
\hline Final products & DC & Customer zone 5 & Customer zone 6 \\
\hline \multirow{2}{*}{1} & 1 & 2950 & 0 \\
& 2 & 1550 & 0 \\
\hline \multirow{2}{*}{2} & 3 & 7200 & 1500 \\
& 1 & 0 & 0 \\
\hline \\
\multirow{2}{*}{3} & 2 & 0 & 2400 \\
\hline
\end{tabular}

Table 17

Amount of seed $(\mathrm{kg})$ supplied to each region

\begin{tabular}{ccccc}
\hline \multirow{2}{*}{ Supplier } & \multirow{2}{*}{ Rice seed } & \multicolumn{2}{c}{ Region } \\
\cline { 3 - 5 } & & Center & West & East \\
\hline Local suppliers & High-yield & 45000 & 22500 & 225000 \\
\hline
\end{tabular}

\section{Table 18}

Amount of fertilizer $(\mathrm{kg})$ supplied to each region

\begin{tabular}{ccccccc}
\hline \multirow{2}{*}{ Region } & \multicolumn{2}{c}{ Urea } & \multicolumn{2}{c}{ Potassium Sulfate } & \multicolumn{2}{c}{ Triple Super Phosphate } \\
\cline { 2 - 6 } & ASSC $^{*}$ & Wholesalers & ASSC & Wholesalers & ASSC & Wholesalers \\
\hline \multirow{2}{*}{ Center } & 140000 & 0 & 150000 & 0 & 0 & 250000 \\
West & 75000 & 0 & 50000 & 0 & 0 & 150000 \\
East & 725000 & 0 & 450000 & 0 & 1000000 & 250000 \\
\hline \multicolumn{2}{r}{ * ASSC: Agricultural Support Services Co. }
\end{tabular}




\section{Sensitivity analysis}

In this section, sensitivity analyses are performed to assess the impact of the changes in the conversion ratio of paddy to rice, available surface water, and costs (rice seeds, fertilizers, pesticides, labor, processing, and transportation) on total profit, and planting area.

\subsection{Effects of changes in conversion ratio}

The main final products of paddies are rice, broken rice, and bran \& husk. Changes in the conversion ratio of paddy to rice in milling centers are expected to affect the amount of production, and thus the total profit of the supply chain. Fig. 3 shows the profit's trend when the conversion ratio of paddy to rice changes by 10, and 20 percent. As presented in Table 19, it is clear that the total profit is positively correlated with the conversion ratio. Rice and broken rice constitute $80 \%$ of the paddies and the ratio of rice and broken rice is dependent on the processing technology used in the milling centers. It is assumed that $10 \%$ percent of paddies would be waste and another $10 \%$ is bran and husk. Increasing the conversion ratio of paddy to rice requires using new technologies at milling centers such as parboiling. This table shows that a $20 \%$ increase in conversion ratio will increase total profit by $82 \%$.

Table 19

Total profit vs. conversion ratio of paddy to final products

\begin{tabular}{ccccc}
\hline Final & \multicolumn{4}{c}{ Conversion ratio } \\
\cline { 2 - 5 } products & $-10 \%$ & $0 \%$ & $+10 \%$ & $+20 \%$ \\
\hline Rice & 0.54 & 0.6 & 0.66 & 0.72 \\
Broken rice & 0.26 & 0.2 & 0.14 & 0.08 \\
Bran and husk & 0.1 & 0.1 & 0.1 & 0.1 \\
Profit & $1.81 \mathrm{E}+11$ & $3.08 \mathrm{E}+11$ & $4.34 \mathrm{E}+11$ & $5.61 \mathrm{E}+11$ \\
Changes in profit (percent) & $-41 \%$ & $0 \%$ & $41 \%$ & $82 \%$ \\
\hline
\end{tabular}

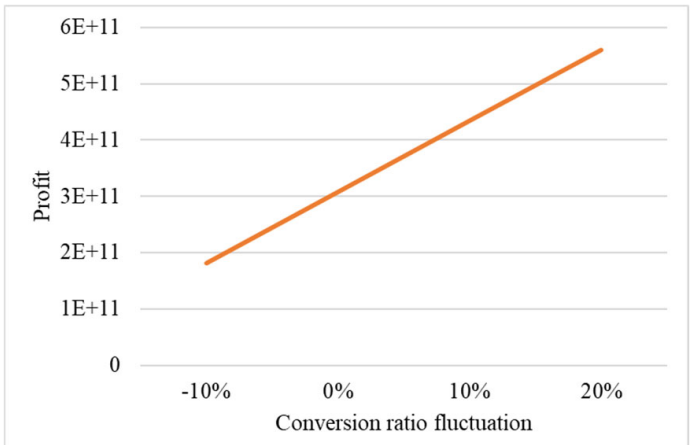

Fig. 3. Total profit vs. conversion ratio

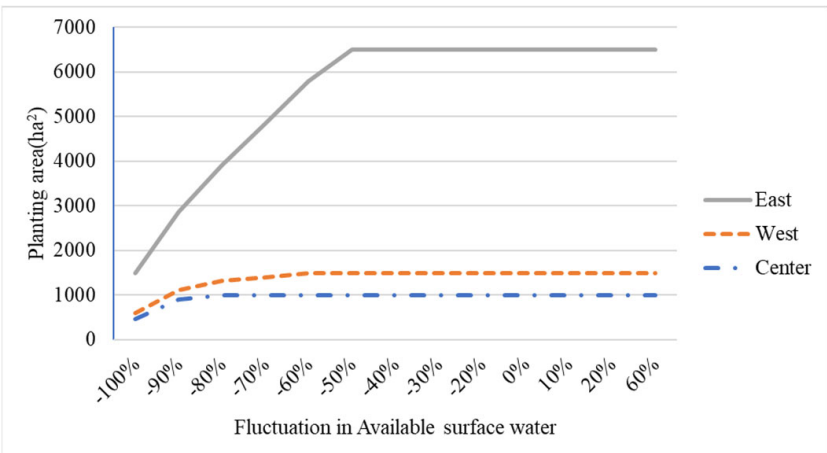

Fig. 4. Optimal planting area vs. available surface water

\subsection{Effects of changes in the available amount of surface water}

Since water is an essential requirement for growing rice, a reduction in the available amount of water will reduce the optimal planting area since irrigation requirements of crops must be fully satisfied. Fig. 4 shows changes in the optimal planting area when available surface water fluctuates. Rice paddies consume more water than other grains such as wheat and corn, thus a reduction in the available amount of water can highly affect production and total profit. The impact of fluctuations in the available amount of surface water on total profit is presented in Table 20. It should be noted that the total profit does not change by increasing the amount of surface water since the available planting area is limited. 
Table 20

Total profit vs. the available amount of surface water

\begin{tabular}{ccccc}
\hline \multirow{2}{*}{ Fluctuation in available surface water } & \multicolumn{3}{c}{ Available surface water } & \multirow{2}{*}{ Profit } \\
\cline { 2 - 4 } & Center & West & Earth & $1.3 \mathrm{E}+11$ \\
\hline$-90 \%$ & $1,434,782.6$ & $317,567.6$ & $3,421,052.6$ & $1.8 \mathrm{E}+11$ \\
$-80 \%$ & $2,869,565.2$ & $635,135.2$ & $6,842,105.2$ & $2.3 \mathrm{E}+11$ \\
$-70 \%$ & $4,304,347.8$ & $952,702.8$ & $10,263,157.8$ & $2.7 \mathrm{E}+11$ \\
$-60 \%$ & $5,739,130.4$ & $1,270,270.4$ & $13,684,210.4$ & $3.05 \mathrm{E}+11$ \\
$-50 \%$ & $7,173,913.0$ & $1,587,838.0$ & $17,105,263.0$ & $3.08 \mathrm{E}+11$ \\
$-40 \%$ & $8,608,695.6$ & $1,905,405.6$ & $20,526,315.6$ & $3.08 \mathrm{E}+11$ \\
$-30 \%$ & $10,043,478.2$ & $2,222,973.2$ & $23,947,368.2$ & $3.08 \mathrm{E}+11$ \\
$-20 \%$ & $11,478,260.8$ & $2,540,540.8$ & $27,368,420.8$ & $3.08 \mathrm{E}+11$ \\
$0 \%$ & $14,347,826.0$ & $3,175,676.0$ & $34,210,526.0$ & $3.08 \mathrm{E}+11$ \\
$10 \%$ & 15782608.6 & 3493243.6 & 37631578.6 & $3.08 \mathrm{E}+11$ \\
$20 \%$ & 17217391.2 & 3810811.2 & 41052631.2 & $3.08 \mathrm{E}+11$ \\
$60 \%$ & 18652173.8 & 4128378.8 & 44473683.8 & \\
\hline
\end{tabular}

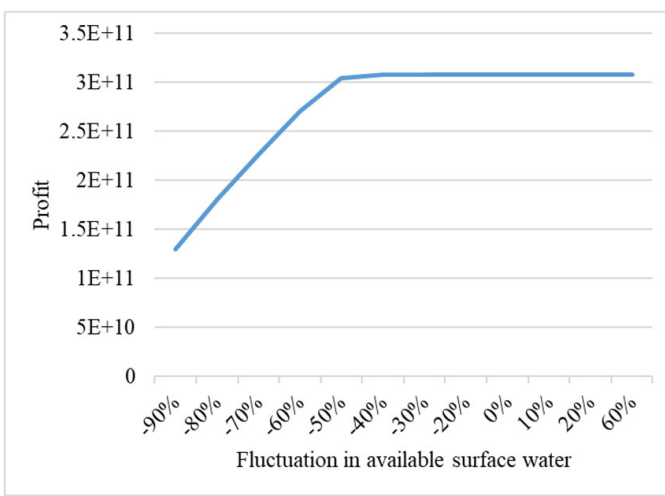

Fig. 5. Profit vs. the available amount of surface water (SW)

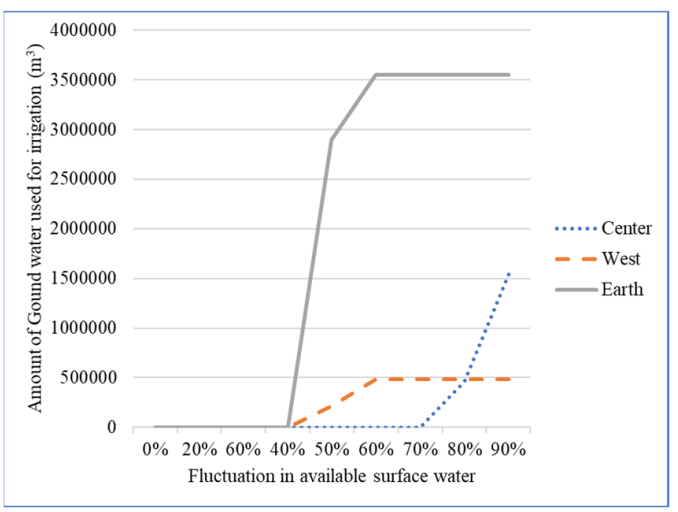

Fig. 6. Groundwater usage vs. the available amount of surface water (SW)

A decrease in the available amount of surface water affects groundwater usage. As shown in Fig. 6, the usage of groundwater starts to increase in different fluctuation points for each region. This analysis is very important as saving groundwater resources in a national issue.

\subsection{Effects of costs' fluctuations on total profit}

Fig. 7 and Fig. 8 show the impact of changes in water costs on the profit. It can be seen from Table 21 and 22 that the profit is less sensitive to fluctuations in groundwater costs in comparison to surface water costs.

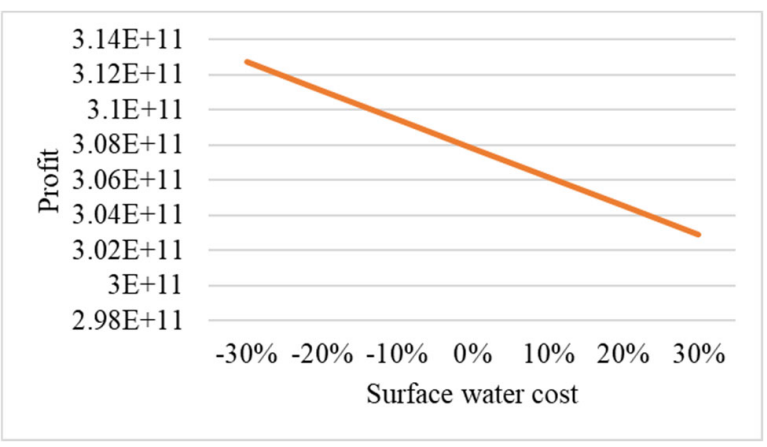

Fig. 8. Total profit vs. surface water cost

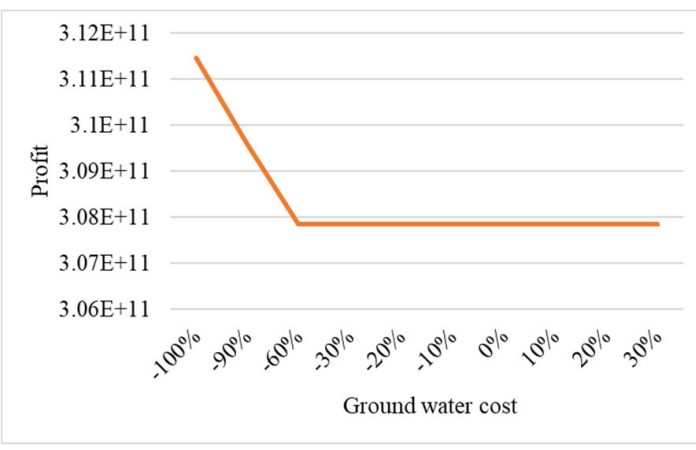

Fig. 7. Total profit vs. groundwater cost 
Table 21

Total profit vs. fluctuations in the cost of surface water

\begin{tabular}{ccccc}
\hline \multirow{2}{*}{ Fluctuation } & \multicolumn{3}{c}{ Regions } & \multirow{2}{*}{ Total profit } \\
\cline { 2 - 3 } & Center & West & Earth & $3.13 \mathrm{E}+11$ \\
$-30 \%$ & 455 & 455 & 455 & $3.11 \mathrm{E}+11$ \\
$-20 \%$ & 520 & 520 & 520 & $3.09 \mathrm{E}+11$ \\
$-10 \%$ & 585 & 585 & 585 & $3.08 \mathrm{E}+11$ \\
$0 \%$ & 650 & 650 & 650 & $3.06 \mathrm{E}+11$ \\
$10 \%$ & 715 & 715 & 715 & $3.05 \mathrm{E}+11$ \\
$20 \%$ & 780 & 780 & 780 & $3.03 \mathrm{E}+11$ \\
\hline $30 \%$ & 845 & 845 & 845 & \\
\hline
\end{tabular}

Table 22

Total profit vs. fluctuations in the cost of groundwater

\begin{tabular}{ccccc}
\hline \multirow{2}{*}{ Fluctuation } & \multicolumn{3}{c}{ Regions } & \multirow{2}{*}{ Total profit } \\
\cline { 2 - 4 } & Center & West & Earth & $3.11 \mathrm{E}+11$ \\
\hline$-100 \%$ & 0 & 0 & 0 & $3.1 \mathrm{E}+11$ \\
$-90 \%$ & 333.4 & 333.4 & 333.4 & $3.08 \mathrm{E}+11$ \\
$-60 \%$ & 666.8 & 666.8 & 666.8 & $3.08 \mathrm{E}+11$ \\
$-30 \%$ & 1166.9 & 1166.9 & 1166.9 & $3.08 \mathrm{E}+11$ \\
$-20 \%$ & 1333.6 & 1333.6 & 1333.6 & $3.08 \mathrm{E}+11$ \\
$-10 \%$ & 1500.3 & 1500.3 & 1500.3 & $3.08 \mathrm{E}+11$ \\
$0 \%$ & 1667 & 1667 & 1667 & $3.08 \mathrm{E}+11$ \\
$10 \%$ & 1833.7 & 1833.7 & 1833.7 & $3.08 \mathrm{E}+11$ \\
$20 \%$ & 2000.4 & 2000.4 & 2000.4 & $3.08 \mathrm{E}+11$ \\
\hline $30 \%$ & 2167.1 & 2167.1 & 2167.1 & \\
\hline
\end{tabular}

Table 23 shows the effects of fluctuations in seed purchasing cost on total profit. The increase in the purchasing cost of rice seeds has led to a decrease in total profit is shown in Fig. 8. It should be noted that seed purchasing cost did not affect the planting area in this analysis.

Table 23

Total profit vs. fluctuations in seed purchasing cost

\begin{tabular}{cccccc}
\hline $\begin{array}{c}\text { Fluctuations in } \\
\text { seed purchasing cost }\end{array}$ & $-30 \%$ & $-10 \%$ & $0 \%$ & $10 \%$ & $40 \%$ \\
\hline Profit & $3.13 \mathrm{E}+11$ & $3.1 \mathrm{E}+11$ & $3.08 \mathrm{E}+11$ & $3.06 \mathrm{E}+11$ & $3.06 \mathrm{E}+11$ \\
\hline
\end{tabular}

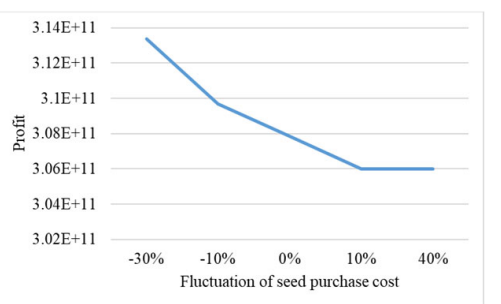

Fig. 8. Profit when seed purchasing cost changes

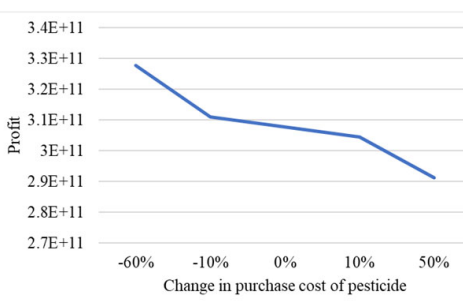

Fig. 9. Profit vs. fluctuations in pesticide purchasing cost

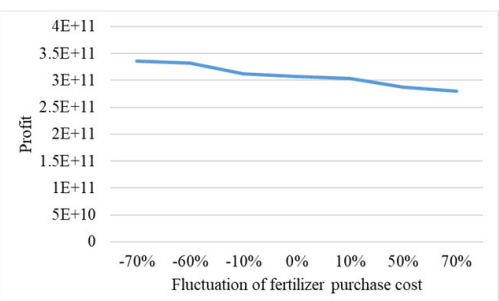

Fig. 10. Profit vs. fluctuations in fertilizer purchasing cost

The increase in pesticide purchasing costs will reduce total profit. Due to the necessity of using pesticides that is indicated in Eq. (25), when pesticide purchasing costs increase, total profit decreases. Also, when fertilizer purchasing cost fluctuates, the behavior of total profit is shown in Fig. 10. The decrease in profit when fertilizer purchasing cost increases, is due to Eq. (23). Labor cost constitutes a substantial portion of total costs, which is about $50 \%$ of total costs in the present case. Therefore, an increase in labor cost has a significant impact on total profit as shown in Fig. 11. Using new technologies for production and processing can reduce the required labor and, thus decreases costs. 
Also, Table 24 shows the impact of labor cost on total profit. Considering a 30\% increase in labor costs decreases profit by $56 \%$.

Table 24

Profit vs. fluctuations in labor cost

\begin{tabular}{cccccc}
\hline & $-20 \%$ & $-10 \%$ & $0 \%$ & $10 \%$ & $30 \%$ \\
\hline Profit & $4.24 \mathrm{E}+11$ & $3.66 \mathrm{E}+11$ & $3.07 \mathrm{E}+11$ & $2.5 \mathrm{E}+11$ & $1.34 \mathrm{E}+11$ \\
\hline
\end{tabular}

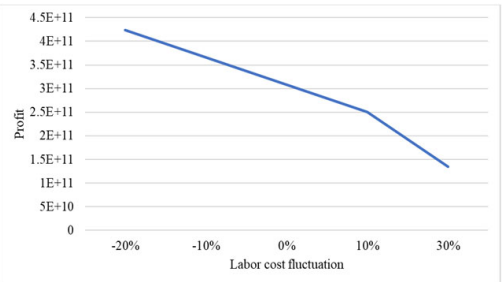

Fig. 11. Profit when labor cost changes

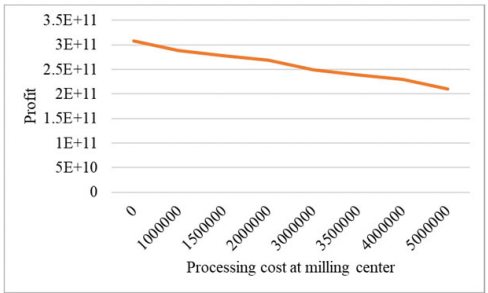

Fig. 12. Sensitivity analysis of processing cost on total profit

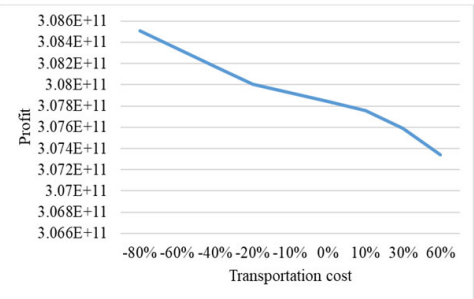

Fig. 13. Profit vs. changes in transportation cost

Fig. 12 shows the impact of changes in processing costs at milling centers on the profit. As the processing cost decreases, the total profit increases. Rice supply chain includes different stages from farmlands to final customers, which requires transportation of products. Therefore, transportation cost is one of the important costs to consider. Fig. 13 shows the total profit when transportation cost changes. It can be seen in this Figure that profit decreases when transportation costs increase. An increase in this cost can affect decision variables such as flow quantities between different facilities, and members of the chain, which reduces production, and profit. The findings of the sensitivity analysis results are presented in the following, which can help managers for decision-making:

- An increase in the conversion ratio of milling centers has a significant effect on total profit. Therefore, investing in new technologies for milling centers such as parboiling is recommended.

- Labor cost constitutes a significant portion of total costs. Therefore, using technologies for cultivation, harvesting, and processing which reduces labor requirements, can reduce costs, and increase total profit.

- Fluctuations in the available amount of surface water can affect the optimal planting area as well. When surface water resources are not sufficient, farmers have to use groundwater which is expensive in comparison to surface water.

- Transportation costs affect the profit of the supply chain. Transportation costs have an effect on the planting area, and thus responsiveness of the chain.

\section{Conclusion and future research opportunity}

Food is one of the most important needs of human beings which is provided in many forms around the world. Agri-food supply chains are composed of different processes that are responsible for bringing food from farm to fork. These processes include cultivation, harvesting, processing, and distribution. In this paper, a mixed-integer linear mathematical model for designing and planning of rice supply chain has been proposed which aims to maximize total profits by integrating different decisions of the rice supply chain including supplier selection, milling center selection, cropping, fertilizing, pest control, harvesting, milling, transportation, and distribution. This model considers different rice varieties and takes into account irrigation water requirements of crops and available water resources. A case study of Iran farmlands in Gilan province is employed to show the applicability and advantages 
of the proposed model for the rice supply chain. The sensitivity analysis results show that the conversion ratio of paddy to final products, the available amount of water, and costs (seed, fertilizer, pesticide, labor, and transportation) have different impacts on the total profit and planting area. It is found that the total profit is positively correlated with the conversion ratio. Also, as the available amount of water increases, planting area and final products increase which leads to profit growth. Different analyses are provided for costs' fluctuations to investigate their impacts on total profit. Labor cost constitutes a substantial portion of total costs, which is about $50 \%$ of total costs in the present case. It should be noted that an increase in labor costs by $30 \%$, leads to a $56 \%$ decrease in total profit. For future studies, considering other decisions such as the location of milling centers and technology selection are recommended. Moreover, future researchers can consider the possibility of contract farming in order to increase planting area and processing capacity. Also, considering different uncertainties that the chain faces can be advantageous.

\section{References}

Ahmadi, T., Mahootchi, M., \& Ponnambalam, K. (2018). Optimal randomized ordering policies for a capacitated two-echelon distribution inventory system. Computers \& Industrial Engineering, 124, 88-99.

Ali, O., Verlinden, B., \& Van Oudheusden, D. (2009). Infield logistics planning for crop-harvesting operations. Engineering Optimization, 41(2), 183-197.

Annetts, J. E., \& Audsley, E. (2002). Multiple objective linear programming for environmental farm planning. Journal of the Operational Research Society, 53(9), 933-943.

Aryanezhad, M. B., \& Jabbarzadeh, A. (2009, July). An integrated model for location-inventory problem with random disruptions. In 2009 International Conference on Computers \& Industrial Engineering (pp. 791-796). IEEE.

Blanco, V., Carpente, L., Hinojosa, Y., \& Puerto, J. (2010). Planning for agricultural forage harvesters and trucks: model, heuristics, and case study. Networks and Spatial Economics, 10(3), 321-343.

Bohle, C., Maturana, S., \& Vera, J. (2010). A robust optimization approach to wine grape harvesting scheduling. European Journal of Operational Research, 200(1), 245-252.

Cai, X., Chen, J., Xiao, Y., \& Xu, X. (2010). Optimization and coordination of fresh product supply chains with freshness-keeping effort. Production and Operations Management, 19(3), 261-278.

Cheraghalipour, A., Paydar, M. M., \& Hajiaghaei-Keshteli, M. (2019). Designing and solving a bilevel model for rice supply chain using the evolutionary algorithms. Computers and Electronics in Agriculture, 162, 651-668.

Clarke, H. R. (1989). Combinatorial aspects of cropping pattern selection in agriculture. European Journal of Operational Research, 40(1), 70-77.

Country Programming Framework (CPF) 2012-2016 for Iran's Agriculture Sector. Available at: http://www.fao.org/3/a-bp603e.pdf [Accessed: 16 October 2019a]

Esmaeilikia, M., Fahimnia, B., Sarkis, J., Govindan, K., Kumar, A., \& Mo, J. (2016). A tactical supply chain planning model with multiple flexibility options: an empirical evaluation. Annals of Operations Research, 244(2), 429-454.

Ferrer, J. C., Mac Cawley, A., Maturana, S., Toloza, S., \& Vera, J. (2008). An optimization approach for scheduling wine grape harvest operations. International Journal of Production Economics, 112(2), 985-999.

Financial tribune. (2015). Iran Top Consumer of Rice, Wheat.[Online] Available at: https://financialtribune.com/articles/people/16952/iran-top-consumer-of-rice-wheat [Accessed: 16 October 2019b]

Higgins, A. J., \& Laredo, L. A. (2006). Improving harvesting and transport planning within a sugar value chain. Journal of the Operational Research Society, 57(4), 367-376.

Hossain, M., \& Jahan, R. (2018). Supply chain improvement and product diversification through integrated zoning of Bangladesh rice milling industry. International Journal of Value Chain Management, 9(2), 187-207. 
Madadi, A., Kurz, M. E., Mason, S. J., \& Taaffe, K. M. (2014). Supply chain design under quality disruptions and tainted materials delivery. Transportation Research Part E: Logistics and Transportation Review, 67, 105-123.

Mangan, J., \& Christopher, M. (2005). Management development and the supply chain manager of the future. The International Journal of Logistics Management, 16(2), 178-191.

Márquez, A. L., Baños, R., Gil, C., Montoya, M. G., Manzano-Agugliaro, F., \& Montoya, F. G. (2011). Multi-objective crop planning using pareto-based evolutionary algorithms. Agricultural Economics, 42(6), 649-656.

Piewthongngam, K., Pathumnakul, S., \& Setthanan, K. (2009). Application of crop growth simulation and mathematical modeling to supply chain management in the Thai sugar industry. Agricultural Systems, 102(1-3), 58-66.

Tan, B., \& Çömden, N. (2012). Agricultural planning of annual plants under demand, maturation, harvest, and yield risk. European Journal of Operational Research, 220(2), 539-549.

Thoucharee, S., Pitakaso, R., \& Phannikul, T. (2017). Application of Modified Differential Evolution for the supply chain management of rice in the lower North-Eastern Region of Thailand. Songklanakarin Journal of Science \& Technology, 39(5).

Van Wart, J., Kersebaum, K. C., Peng, S., Milner, M., \& Cassman, K. G. (2013). Estimating crop yield potential at regional to national scales. Field Crops Research, 143, 34-43.

Zhang, M., \& Li, P. (2012). RFID application strategy in agri-food supply chain based on safety and benefit analysis. Physics Procedia, 25, 636-642.

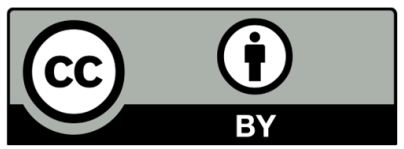

(C) 2020 by the authors; licensee Growing Science, Canada. This is an open access article distributed under the terms and conditions of the Creative Commons Attribution (CC-BY) license (http://creativecommons.org/licenses/by/4.0/). 